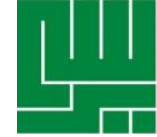

KATA KUNCI

KEYWORDS

ABSTRAK

ABSTRACT

\section{Hubungan Psychological Well-Being dengan Loneliness pada Mahasiswa yang Merantau}

\section{Relationship between Psychological Well-Being and Loneliness among Overseas Student}

\author{
Cindy Frencya Halim ${ }^{1} \&$ Agoes Dariyo ${ }^{2}$ \\ Fakultas Psikologi Universitas Tarumanagara \\ JL Letjen S Parman,No. 1 Jakarta Barat 11440 \\ Email: cindy.frencya@ymail.com; agoesd@fpsi.untar.ac.id
}

kesejahteraan psikologis, kesepian, mahasiswa rantau

psychological well-being, loneliness, overseas student

Pada zaman sekarang, banyak mahasiswa merantau demi menempuh pendidikan yang lebih baik. Hal tersebut terjadi karena penyebaran pendidikan yang belum merata di Indonesia, pendidikan yang baik banyak terdapat di Pulau Jawa. Perpindahan ke lingkungan baru dapat menyebabkan mahasiswa tersebut mengalami perasaan loneliness. Pada beberapa penelitian sebelumnya, terlihat adanya hubungan pada psychological well-being dengan loneliness. Jadi penelitian ini bertujuan untuk melihat hubungan antara psychological wellbeing dengan loneliness pada subyek yang berbeda yaitu mahasiswa rantau. Penelitian ini adalah penelitian kuantitatif dengan teknik pengambilan data accidental sampling. Subyek penelitian ini adalah mahasiswa rantau berusia 18-21 tahun di Jakarta. Alat ukur penelitian ini adalah dengan menggunakan kuisioner psychological well-being berdasarkan skala Ryff dan alat ukur loneliness. Kuisioner dibagikan kepada 405 orang responden dengan laki-laki sebanyak 108 orang dan perempuan 297 orang yang mewakili mahasiswa yang merantau di Jakarta. Berdasarkan hasil olah data dengan menggunakan SPSS 22.00 ditemukan bahwa korelasi antara psychological well-being dengan loneliness ( $r=-0.659 ; p=0.000<0.005)$ yang berarti terdapat hubungan negatif yang signifikan antara psychological well-being dengan loneliness. Setiap dimensi psychological wellbeing juga memiliki hubungan yang negatif dan signifikan terhadap loneliness.

At recent days, many overseas students study in Java island because education quality in Java is better than other islands in Indonesia. Moving to the new place can possibly made someone become loneliness. In previous research, there was relationship between psychological well-being and loneliness. Hence, the aim of this research was to investigate the relationship between psychological well-being and loneliness especially among overseas students. This research was quantitative research using accidental sampling technique for the sample of research. The 
sample of this research was 18-21 years old overseas students who studied in Jakarta. Data were collected with standardized questionnaire that contained psychological well-being scale by Ryff and loneliness scale. The questionnaires were administrated to 405 participants comprises 108 male and 297 female respectively that were randomly selected across University in Jakarta. The finding of this research indicated that psychological well-being among overseas student had correlation with loneliness (correlated range $r=-0.659$ and $p=0.000<0.005$ ). Hence, psychological well-being has negative correlation with loneliness and each dimension of psychological well-being also has negative correlation with loneliness.

\section{PENDAHULUAN}

Pada zaman globalisasi ini, banyak mahasiswa yang menempuh pendidikan tinggi di luar kampung halamannya, sehingga mereka harus tinggal di luar rumah atau luar daerah dalam jangka waktu tertentu demi menyelesaikan pendidikannya atau disebut dengan istilah mahasiswa merantau. Mahasiswa adalah orang yang belajar di perguruan tinggi. Menurut Kementrian Pendidikan dan Kebudayaan (2015), mahasiswa yang merantau dapat diartikan sebagai orang yang belajar di perguruan tinggi yang terletak di luar daerah asalnya, sehingga mereka harus tinggal di luar rumah dalam jangka waktu tertentu untuk menyelesaikan pendidikannya.

$\begin{array}{ccc}\text {. Salah satu alasan mahasiwa } \\ \text { merantau } & \text { dikarenakan kualitas }\end{array}$ pendidikan yang belum merata pada setiap wilayah Indonesia, karena perguruan-perguruan tinggi yang berkualitas masih didominasi oleh perguruan tinggi di Pulau Jawa ("PT Berkualitas Belum Merata”, 2008). Selain itu, data sepuluh perguruan tinggi negeri dan swasta terbaik di Indonesia ternyata semuanya terletak di Pulau Jawa. Salah satu penyebabnya masih kurangnya tenaga pendidik atau dosen yang berkualitas di berbagai daerah. ("Dosen Berkualitas di NTT Masih Kurang”, 2015).

Data dari Badan Pusat Statistik (2015) menunjukkan bahwa pada periode 2013/2014 Jakarta merupakan provinsi dengan mahasiswa terbanyak karena jumlah keseluruhan mahasiswa di perguruan tinggi negeri maupun swasta adalah 1.154.966 mahasiswa. Untuk tenaga pendidik Badan Pusat Statistik (2015) menyatakan bahwa Jakarta menempati posisi ketiga setelah provinsi Jawa Timur dan Jawa Barat dengan jumlah tenaga pendidik sebanyak 26.903 orang. Tidak meratanya kualitas perguruan tinggi di Indonesia menyebabkan banyaknya mahasiswa yang pindah dari kota asalnya untuk menimba ilmu yang lebih baik di wilayah Pulau Jawa.

Irawati (2013) juga mengatakan bahwa salah satu alasan merantau adalah untuk mendapatkan pendidikan yang layak. Pendidikan yang layak merupakan hak masyarakat Indonesia. Jika di daerahnya tidak memiliki tempat pendidikan yang layak maka individu akan merantau untuk meraih cita-citanya. Oleh karena itu, para perantau sering ditemukan di kampuskampus di seluruh Indonesia yang 
kebanyakan adalah mahasiswa. Awalnya mereka hanya merantau untuk menggapai cita-citanya dalam hal pendidikan, tetapi akhirnya mereka tidak pulang ke daerah asal. Individu yang merantau akan tetap tinggal di tempat merantau untuk bekerja.

Pada tahun 2010, Mental Health Foundation menemukan bahwa loneliness lebih banyak terjadi pada anak muda dibandingkan orang dewasa atau orang tua. Berdasarkan survei, usia 18-34 tahun lebih sering mengalami kesepian, cemas akan perasaan kesepian, dan merasa depresi karena kesepian dibandingkan dengan kelompok usia diatas 55 tahun (dalam Gil, 2014). Selain itu, penelitian Perlman (dalam Taylor, Peplau, \& Sears, 2006) juga menyatakan bahwa loneliness lebih banyak terjadi pada remaja dan dewasa awal dibandingkan individu dengan usia yang lebih tua.

Penelitian dari Heinrich dan Gullone (Goossens, Klimstra, Luyckx, Vanhalst, dan Teppers, 2014) menyatakan bahwa remaja akhir yang sudah memasuki universitas, memiliki tingkatan loneliness yang lebih tinggi. Hal ini disebabkan karena dewasa awal banyak mengalami transisi sosial seperti meninggalkan rumah, tinggal seorang diri, memasuki masa kuliah, atau memasuki dunia kerja. Semakin bertambahnya usia maka kehidupan sosial lebih stabil, kemampuan sosial juga lebih baik, dan lebih realistis dalam ekspektasi tentang hubungan sosial (Taylor, Peplau, \& Sears, 2006).

Loneliness dapat terjadi di kalangan mahasiswa apalagi mahasiswa yang merantau karena tinggal di luar kampung halamannya dan jauh dari orang tua. Loneliness memiliki beberapa dampak yaitu kesehatan fisik, kesehatan mental, maupun fungsi kognitif. Dampak pada kesehatan fisik seperti peningkatan resiko kesehatan kardiovaskular terutama pada dewasa muda dan juga meningkatkan tekanan darah sistol (keadaan dimana jantung berdetak atau kontraksi, lalu darah akan terdorong melalui arteri ke seluruh tubuh) pada dewasa tengah. Loneliness diasosiasikan dengan gangguan kepribadian dan psikosis, penurunan performa kognitif, meningkatkan kemungkinan penyakit alzheimer, menghilangkan kontrol eksekutif, dan meningkatkan gejala depresi (Hawkley \& Cacioppo, 2010). Loneliness dapat dialami oleh para mahasiswa merantau karena terkait dengan psychological well being (Cecen dan Cenkseven, 2007; Nanda (2013). Berdasarkan uraian di atas, mahasiswa yang merantau kemungkinan dapat merasakan loneliness karena perubahan lingkungan yang terjadi. Lalu pada usia emerging adult seperti mahasiswa, akan lebih rentan mengalami loneliness. Namun, faktanya tidak semua mahasiswa merantau akan mengalami loneliness tersebut. Loneliness memiliki berbagai dampak negatif bagi seorang individu, sedangkan psychological well-being merupakan kehidupan yang positif dan seimbang. Penelitian dengan kedua variabel tersebut pada subyek mahasiswa yang merantau masih belum pernah diteliti tepatnya di Indonesia. Oleh karena itu, peneliti ingin mengetahui hubungan antara psychological well-being dan loneliness pada mahasiswa yang merantau. 


\section{Psychological well-being}

Ryff (1989) memaparkan bahwa psychological well-being (atau yang sering disingkat PWB), merupakan konstruksi multidimensional yang terbentuk dari sikap terhadap hidup seseorang. Gambaran tentang karakteristik orang yang memiliki kesejahteraan psikologis merujuk pada pandangan Rogers tentang orang yang mampu berfungsi secara penuh (fullyfunctioning person), pandangan Maslow tentang aktualisasi diri (self actualization), pandangan Jung tentang individuasi, konsep Allport tentang kematangan, juga sesuai dengan konsep Erikson dalam menggambarkan individu yang mencapai integrasi dibanding putus asa (integrity versus despair). Ryff (1989) menjelaskan bahwa psychological well-being merupakan suatu konsep yang berkaitan dengan apa yang dirasakan individu mengenai aktivitas dalam kehidupan sehari-hari, serta mengarah pada pengungkapan perasaan-perasaan pribadi atas apa yang dirasakan oleh individu sebagai hasil dari pengalaman hidupnya. Enam dimensi psychologcical well-being menurut Ryff (dikutip dalam Compton, 2005) adalah self-acceptance (penerimaan diri), personal growth (pertumbuhun diri), positive relations with others (relasi yang positif dengan orang lain), autonomy (otonomi), purpose in life (tujuan dalam hidup), dan environmental mastery (penguasaan diri).

\section{Loneliness}

Weiss (dalam Sønderby \& Wagoner, 2013) menyatakan bahwa loneliness adalah suatu kondisi bukan disebabkan karena individu sedang sendiri melainkan karena kurangnya hubungan atau rangkaian hubungan yang dibutuhkan. Loneliness merupakan sebuah respon dari hilangnya atau ketidakhadirannya sebuah hubungan yang dekat. Definisi lain dari loneliness adalah perasaan kegelisahan psikologis yang inidividu rasakan ketika hubungan sosial mengalami kekurangan dalam beberapa aspek penting. Kekurangan ini dapat berupa secara kuantitatif yaitu kurangnya hubungan atau kualitatif seperti hubungan yang tidak menyenangkan (Taylor, Peplau, \& Sears, 2006). Selain itu, menurut Myers (2010) loneliness walaupun kronik atau temporer, adalah kesadaran yang menyakitkan bahwa hubungan sosial yang dimiliki kurang berarti atau bermakna dibandingkan yang diharapkan. Weiss (dalam Taylor, Peplau, \& Sears, 2006) membagi loneliness menjadi dua tipe, yaitu emotional loneliness dan social loneliness. Emotional loneliness adalah kesepian yang disebabkan oleh kurangnya atau tidak adanya kelekatan intim pada suatu tokoh atau sosok seperti anak kecil dengan orangtuanya atau seorang individu dewasa dengan pasangannya atau teman dekat. Sedangkan social loneliness terjadi ketika individu mengalami perasaan kurang dalam integrasi atau keterlibatan sosial yang dapat diperoleh dari teman atau teman kerja (Taylor, Peplau, \& Sears, 2006). Miller, Pelpman, dan Brehm (2007) menyebutkan bahwa terdapat empat penyebab loneliness yaitu kekurangan dalam hubungan, perubahan yang diinginkan dari sebuah hubungan, 
atribusi kausal, dan perilaku interpersonal.

\section{Emerging adulthood}

Menurut Arnett (dalam Santrock, 2008) transisi dari masa remaja ke masa dewasa disebut dengan emerging adulthood, yang terjadi pada usia 1825 tahun. Pada masa perkembangan ini, individu sedang mengeksplorasi jalan karir, identitas, dan gaya hidup. Begitupun menurut Kail dan Cavanaugh (2013) yang menjelaskan juga bahwa emerging adulthood adalah periode antara remaja akhir dan usia 20-an ketika individu bukan lagi remaja namun juga bukan dewasa. Pada masa ini, selain mengeksplor karir dan dentitas diri, individu juga mengeksplor komitmen. Lima karakteristik emerging adulthood menurut Arnett (dalam Santrock, 2008) yaitu eksplorasi identitas, instability, self-focused, feeling in-between, dan age of possibilities.

\section{Hipotesis}

Hipotesis dari penelitian ini adalah terdapat hubungan antara psychological well-being dengan loneliness pada mahasiswa yang merantau.

\section{METODE PENELITIAN}

\section{Karakteristik dan Jumlah Subyek Penelitian}

Subyek penelitian ini memiliki karakteristik, yaitu mahasiswa rantau, berjenis kelamin pria atau wanita dengan rentang usia kira-kira 18-21 tahun yang sedang menempuh masa studi di sebuah universitas di Jakarta. Jumlah responden yang berjenis kelamin laki-laki sebanyak 108 orang $(26,7 \%)$ dan jumlah responden yang berjenis kelamin perempuan sebanyak 297 orang $(73,3 \%)$. Dengan demikian jumlah keseluruhan responden pada penelitian ini adalah sebanyak 405 responden.

\section{Teknik Pengambilan Data}

Penelitian ini menggunakan teknik pengambilan sampel non-probabilitas sampling. Jenis penarikan sampel yang digunakan adalah accidental sampling yaitu sampel diambil secara kebetulan tanpa direncanakan oleh peneliti. Jadi, siapapun yang ditemukan peneliti dapat dijadikan sampel jika sesuai dengan kriteria subyek penelitian.

\section{Alat Ukur Penelitian}

Dalam penelitian ini digunakan dua alat ukur yaitu untuk mengukur tingkat loneliness dan psychological wellbeing. Alat ukur loneliness dibuat sendiri oleh peneliti agar sesuai dengan konteks penelitian. Alat ukur memiliki 27 butir pertanyaan yang mewakili perasaan loneliness. Sedangkan alat ukur psychological well-being menggunakan alat ukur dari Ryff (1989) dengan 42 butir pernyataan yang juga diterjemahkan ke bahasa Indonesia. Alat ukur PWB mengukur enam dimensi PWB yaitu selfacceptance, personal growth, relasi yang positif dengan orang lain, autonomy, tujuan dalam hidup, dan environmental mastery. Pengukuran dilakukan pada mahasiswa rantau tahun pertama sesuai dengan metode penelitian kuantitatif. Penulis memakai skala likert untuk melakukan proses penelitian. Skala likert sendiri adalah skala dengan lima pilihan jawaban yaitu SS (sangat sesuai), S (sesuai), AS (agak sesuai), TS (tidak sesuai), STS 
(sangat tidak sesuai), yang digunakan untuk mengukur sikap, pendapat, atau persepsi seseorang atau sekelompok individu mengenai suatu fenomena.

Adapun reliabilitas kuisioner psychological well-being: dimensi 1 (otonomi) dengan alpha cronbach $(\alpha)$ $=0.726$; dimensi 2 (pertumbuhan diri) dengan alpha cronbach $(\alpha)=0.601$; dimensi 3 (tujuan hidup) alpha cronbach $(\alpha)=0.730 ;$ dimensi 4 (relasi positif) alpha cronbach $(\alpha)=$ 0.649 ; dimensi 5 (penerimaan diri) alpha cronbach $(\alpha)=0.712$; dimensi 6 (penguasaan lingkungan) alpha cronbach $(\alpha)=0.571$. Salah satu item adalah "Saya berani memberikan pendapat saya, walaupun berbeda dengan kebanyakan orang". Lalu untuk reliabilitas kuisioner loneliness dengan alpha cronbach $(\alpha)=0.943$. Salah satu item adalah "Saya sulit mempunyai teman yang cocok dengan saya".

\section{Pengolahan dan Teknik Analisis Data}

Sebelum dilakukan analisis data utama, perlu dilakukan uji asumsi, yaitu: uji normalitas dan uji linearitas terlebih dahulu. Bila terpenuhi uji asumsi, maka dilanjutkan dengan uji hipotesis. Analisis data menggunakan program komputer SPSS versi 22.00 dengan jenis penelitian korelasi untuk mengetahui apakah terdapat hubungan loneliness dengan psychological wellbeing secara signifikan atau tidak. Metode yang digunakan adalah metode korelasi Pearson.

\section{ANALISIS DAN HASIL}

Sebelum melakukan analisis data utama, yang pertama dilakukan terlebih dahulu uji normalitas dan uji linearitas. Untuk uji normalitas menggunakan uji Kolmogorov-smirnov dengan nilai $\mathrm{z}=0.614$ dan $\mathrm{p}=0.846>0.05$ yang menunjukkan data terdistribusi normal. Sedangkan, uji linearitas didapatkan data $\mathrm{F}=0.895$ dan $\mathrm{p}=0.708>0.05$ yang menunjukkan data linear. Setelah uji asumsi terpenuhi dengan baik, dilakukan uji data utama untuk menguji hipotesis penelitian. Uji korelasi menggunakan uji Pearson dengan program SPSS versi 22.00. Pengujian korelasi antara psychological well-being dengan loneliness dilakukan dengan menggunakan perhitungan korelasi Pearson. Hasil perhitungan menunjukkan bahwa $r=-0.659$ dan $\mathrm{p}=0.000<0.05$. Dengan demikian terdapat hubungan negatif dan signifikan antara psychological wellbeing dengan loneliness. Hal ini berarti semakin tinggi psychological wellbeing maka kecenderungan mahasiswa untuk memiliki perasaan loneliness semakin rendah. Demikian pula sebaliknya semakin rendah psychological well-being semakin tinggi mahasiswa untuk memiliki perasaan loneliness.

Selanjutnya dilakukan uji korelasi antara setiap dimensi psychological well-being dengan loneliness. Pengujian korelasi menggunakan perhitungan korelasi Pearson. Hasil analisa data menunjukkan bahwa seluruh dimensi dalam psychological well-being mempunyai hubungan negatif dan signifikan dengan perasaan loneliness. Dimensi otonomi 
berkorelasi dengan loneliness dibuktikan dari data $\mathrm{r}=-0.162$ dan $\mathrm{p}=$ $0.001<0.05$, dimensi pertumbuhan diri berkorelasi loneliness dibuktikan dari data dengan $\mathrm{r}=-0.471$ dan $\mathrm{p}=$ $0.000<0.05$, dimensi relasi positif berkorelasi dengan loneliness dibuktikan dari data $\mathrm{r}=-0.689$ dan $\mathrm{p}=$ $0.000<0.05$, dimensi tujuan hidup berkorelasi dengan loneliness dibuktikan dari data $\mathrm{r}=-0.503$ dan $\mathrm{p}=$
$0.000<0.05$, dimensi penerimaan diri dengan loneliness dibuktikan dari data $\mathrm{r}=-0.520$ dan $\mathrm{p}=0.000<0.05$, dan dimensi penguasaan lingkungan berkorelasi dengan loneliness dibuktikan dari data $\mathrm{r}=-0.454$ dan $\mathrm{p}=$ $0.000<0.05$. Tabel 1 menunjukan data hasil korelasi setiap psychological well-being dengan loneliness.

Tabel 1. Korelasi Loneliness dengan Dimensi Psychological Well-Being

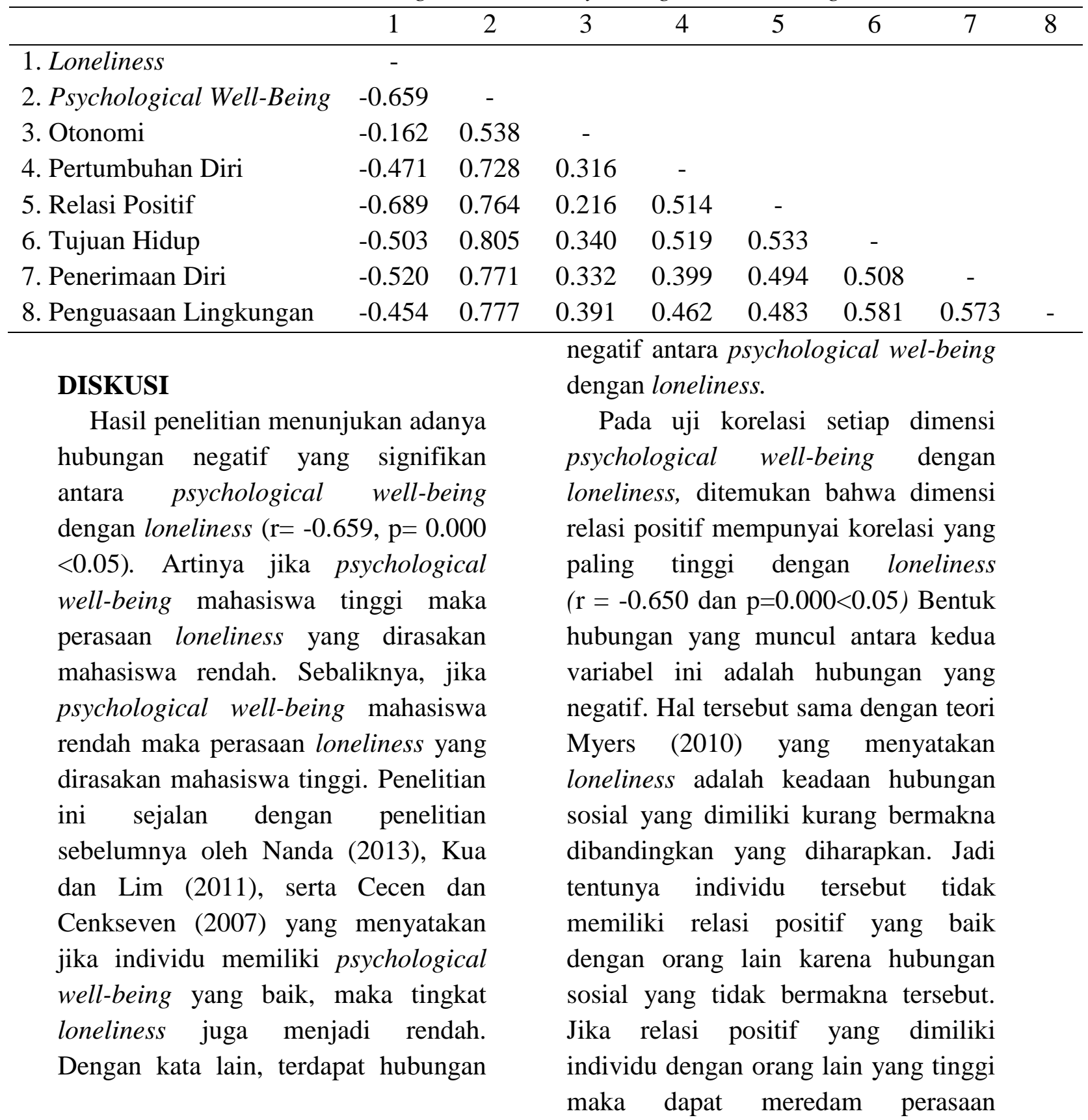


loneliness yang akan muncul pada individu.

Dimensi penerimaan diri juga memiliki hubungan dengan loneliness $(\mathrm{r}=-0.520$ dan $\mathrm{p}=0.000<0.05)$. Jika seseorang dapat menerima dirinya dengan baik, tentu individu tidak akan mengalami loneliness. Hal ini sejalan dengan penelitian Basiroh (2007) yang menyatakan hal yang serupa yaitu memang penerimaan diri memiliki hubungan yang negatif dengan loneliness. Selanjutnya dimensi tujuan hidup memiliki hubungan yang negatif juga dengan $r=-0.503$ dan $\mathrm{p}=0.000<0.05$. Loneliness memang dapat menyebabkan individu tidak memiliki tujuan hidup. Hal ini sejalan dengan Killeen (1998) yang menyatakan bahwa loneliness berkaitan dengan individu merasa tidak berguna dan terisolasi bahkan menyebabkan hidup individu tidak memiliki tujuan. Pisca dan Feldman (2009) menyatakan bahwa individu yang memiliki tujuan hidup akan aktif dalam mencapai tujuan tersebut seperti mengatur lingkungan sekitar agar dapat mencapai tujuan dan arti dari makna hidupnya. Setelah individu memiliki tujuan, nilai, kepercayaan diri, dan keberhargaan diri, individu akan terhindar dari munculnya perasaan frustasi, perasaan tidak enak, ketidakpuasan, atau ketidakstabilan. Dari paparan di atas, dapat dilihat bahwa memang ada hubungan yang negatif antara tujuan hidup dengan loneliness.

Pada dimensi otonomi juga memiliki hubungan yang negatif dengan loneliness $(\mathrm{r}=-0.162$ dan $\mathrm{p}=$ $0.001<0.05$ ). Individu yang otonom tentunya melakukan sesuatu sesuai dengan keinginan dan nilai yang dimiliki individu tersebut. Individu mengerjakan sesuatu sendiri dengan integrasi antara motivasi intrinsik (dari dalam diri individu) dan motivasi ekstriksik (dari luar individu/lingkungan) yang baik. Individu yang memiliki motivasi intrinsik dan ekstrinsik dalam otonomi yang baik akan memiliki kesehatan psikologi yang baik. Sebaliknya, jika individu tidak memiliki motivasi otonomi yang baik akan memiliki psychological well-being yang rendah (Roth \& Deci, 2009). Berdasarkan paparan di atas, dapat dilihat bahwa jika individu tidak otonom akan menyebabkan psychological-well being yang rendah. Psychological well-being memiliki hubungan yang negatif dengan loneliness. Jadi jika otonomi rendah maka loneliness cenderung tinggi begitupun sebaliknya.

Dimensi selanjutnya yaitu pertumbuhan diri juga memiliki hubungan yang negatif dengan loneliness $(\mathrm{r}=-0.471$ dan $\mathrm{p}=$ $0.000<0.05)$. Individu yang memiliki pertumbuhan diri artinya sadar dengan pertumbuhan dan perubahan yang terjadi dalam dirinya (Robitschek \& Spering, 2009). Individu yang sadar dengan perubahan dalam dirinya akan terbuka dan merespon positif pada perubahan lingkungan yang terjadi karena hal tersebut dapat mebuat individu tersebut dapat bertumbuh juga. Respon positif yang diberikan individu akan meminimalkan munculnya perasaan loneliness. Jadi jika pertumbuhan diri tinggi maka loneliness rendah begitupun sebaliknya. 
Dimensi yang terakhir yaitu penguasaan lingkungan juga memiliki hubungan yang negatif dengan loneliness $(\mathrm{r}=-0.454$ dan $\mathrm{p}=$ $0.000<0.05)$. Individu yang memiliki penguasaan lingkungan yang baik akan dapat menciptakan lingkungan yang sesuai dengan dirinya untuk mencapai suatu tujuan. Individu yang memiliki lingkungan yang sesuai dengan dirinya akan menjadi lebih senang, produktif, dan secara psikologis lebih sehat dibandingkan dengan individu yang tidak memiliki lingkungan yang sesuai dengan dirinya. Oleh karena itu, ada keterkaitan antara individu dengan lingkungannya untuk mencapai suatu tujuan (Walsh, 2009). Berdasarkan paparan di atas, individu yang memiliki penguasaan lingkungan yang baik juga memiliki kesehatan psikologis yang baik sedangkan hubungan psychological well-being dengan loneliness adalah negatif. Jadi secara tidak langsung, jika penguasaan lingkungan tinggi maka loneliness rendah dan begitupun sebaliknya.

\section{SIMPULAN}

Dari analisis penelitian yang telah dipaparkan di atas, dapat ditarik simpulan bahwa terdapat hubungan negatif yang signifikan antara psychological well-being dengan loneliness pada mahasiswa yang merantau. Artinya jika psychological well-being mahasiswa tinggi maka perasaan loneliness yang dirasakan mahasiswa rendah. Sebaliknya, jika psychological well-being mahasiswa rendah maka perasaan loneliness yang dirasakan mahasiswa tinggi. Selain itu untuk setiap dimensi psychological well-being yaitu autonomy, personal growth, purpose in life, positive relation with others, self-acceptance, dan environmental mastery juga memiliki hubungan yang negatif dan signifikan dengan loneliness. Artinya jika dimensi pada psychological wellbeing mahasiswa tinggi maka perasaan loneliness yang dirasakan mahasiswa rendah. Sebaliknya, jika dimensi pada psychological well-being mahasiswa rendah maka perasaan loneliness yang dirasakan mahasiswa tinggi.

\section{SARAN}

Saran secara praktis diberikan kepada mahasiwa maupun orang tua agar terhindar dari munculnya perasaan loneliness pada mahasiswa yang merantau dengan memiliki psychological well-being yang baik. Saran bagi mahasiswa rantau untuk mengetahui tentang loneliness yang memang dapat muncul jika berada pada suatu lingkungan yang baru dan penyebab lainnya sehingga tidak mengalami perasaan loneliness tersebut. Salah satu caranya adalah dengan memiliki psychological wellbeing yang baik, terutama pada dimensi relasi positif dengan orang lain. Dengan memiliki relasi yang baik dengan orang sekitar, dapat membantu untuk mencegah terjadinya perasaan loneliness.

Saran selanjutnya adalah untuk mahasiswa lainnya yang tidak merantau agar dapat memberikan dukungan agar tidak terjadi loneliness pada mahasiswa rantau. Seperti yang telah didipaparkan sebelumnya bahwa dengan memiliki relasi positif dengan orang lain dapat mengurangi terjadinya perasaan loneliness. Bagi orangtua diharapkan mengetahui kondisi anak 
apalagi yang tidak tinggal bersama agar psychological well-being anak pun tetap baik. Salah satu yang dimaksud dengan relasi positif dengan orang lain juga berarti dengan orang tua walau tinggal berjauhan. Namun dengan adanya relasi yang baik dengan orang tua setidaknya membantu mengurangi perasaaan loneliness yang dapat dirasakan mahasiswa rantau.

Saran untuk penelitian selanjutnya adalah dapat menambahkan uji pengaruh pada psychological wellbeing terhadap loneliness. Lalu, variabel loneliness dapat ditinjau lebih dalam pada beberapa dimensinya seperti sosial atau emosional serta temporer atau kronis agar lebih tergambar lebih jelas dan mendalam.

\section{DAFTAR PUSTAKA}

Agustin, I. M. (2009). Studi deskriptif mengenai derajat psychological wellbeing pada mahasiswa fakultas psikologi universitas ' $X$ ' Bandung. (Skripsi, Universitas Maranatha). Diunduh dari http://repository.maranatha.edu/8671/

Aprianti, I. (2012). Hubungan antara perceived social support dan psychological well-being pada mahasiswa perantau tahun pertama di Universitas Indonesia. (Skripsi, Universitas Indonesia). Diunduh dari http://lib.ui.ac.id/file?file=digital/20320 186-S-Indah\%20Aprianti.pdf

Arnett, J. J. (2004). Emerging adulthood: The winding road from the late teens through the twenties. New York, NY: Oxford University Press.

Badan Pusat Statistik. (2015). Jumlah perguruan tinggi, mahasiswa, dan tenaga edukatif (negeri dan swasta) di bawah kementrian pendidikan dan kebudayaan menurut provinsi 2013/2014. BPS. Diunduh dari
Selain itu, variabel seperti dukungan sosial dapat menjadi moderator antara psychological well-being dengan loneliness. Pengaruh budaya maupun etnis juga dapat menjadi variabel kontrol agar hasil penelitian lebih lengkap.

Secara metode penelitian, penelitian secara kuantitatif yang dilakukan oleh peneliti kurang dapat menggali lebih dalam mengenai fenomena loneliness dan psychological well-being yang dimiliki responden. Dengan demikian, nampaknya penelitian secara kualitatif seperti wawancara secara terstruktur dapat ditambahkan agar membantu melihat dan menggali lebih dalam mengenai fenomena psychological well-being dengan loneliness tersebut.

http://www.bps.go.id/linkTabelStatis/vi ew/id/1839

Basiroh, L. (2007). Hubungan antara penerimaan diri dengan kesepian pada lanjut usia. (Skripsi tidak dipublikasi). Universitas Ahmad Dahlan, Yogyakarta.

Cecen, A. R., \& Cenkseven, F. (2007). Psychological well-being in predicting loneliness among university students. Ç.Ü. Sosyal Bilimler Enstitüsü Dergisi, 16(2), 109-118.

Cohen, R. J., Swerdlik, M. E., \& Sturman, E. D. (2010). Psyhological testing and assessment: An introduction to tests and measurement. New York, NY: McGraw-Hill.

Compton, W.C. (2005). An introduction to positive psychology. Belmont, CA: Thomson Wadsworth.

Dewa, A. R. (2015). Dukungan sosial dengan subjective well being pada mahasiswa perantau dari luar jawa tahun pertama. (Skripsi, Universitas Gajah Mada). Diunduh dari 
http://etd.repository.ugm.ac.id/index.ph p?act=view\&buku_id=79320\&mod=pe nelitian_detail\&sub=PenelitianDetail\&t $\mathrm{yp}=\mathrm{html}$

Dosen Berkualitas di NTT Masih Kurang. (2015, Juni 8). Okezone. Diunduh dari http://news.okezone.com/read/2015/06/ 08/65/1161845/dosen-berkualitas-dintt-masih-kurang

Franzoi, S. (2012). Social psychology (6th ed.). Redding, CA: BVT Publishing.

Gil, N. (2014, 20 Juli). Loneliness: A silent plague that is hurting young people most. Theguardian. Diunduh dari

http://www.theguardian.com/lifeandsty le/2014/jul/20/loneliness-britainssilent-plague-hurts-young-people-most

Goossens, L., Klimstra, T., Luyckx, K., Vanhalst, J., \& Teppers, E. (2014). Reliability and validity of the roberts UCLA loneliness scale (RULS-8) with dutch-speaking adolescents in Belgium. Psychologica Belgica, 54(1), 5-18, doi: http://dx.doi.org/10.5334/pb.ae

Gunarsa, S. D., \& Gunarsa, Y. S. D. (2004). Psikologi praktis: Anak, remaja, dan keluarga. Jakarta: BPK Gunung Mulia.

Hawkley, L. C., \& Cacioppo, J. T. (2010). Loneliness matters: A theoretical and empirical review of consequences and mechanisms. Annals of Behavioral Medicine, 40(2), 218-227. doi: 10.1007/s12160-010-9210-8.

Heinrich, L. M., \& Gullone, E. (2006). The clinical significance of loneliness: A literature review. Clinical Psychology Review, 26, 695-718. doi: 10.1016/j.cpr.2006.04.002

Irawati, S. D. (2013, 22 September). 6 alasan mereka merantau. Kompasiana. Diunduh dari http://www.kompasiana.com/suciana/6alasan-merekamerantau_5528f9986ea834b15b8b4590

Kail, R. V., \& Cavanaugh, J. C. (2013). Human development: A life-span view (6th ed.). Belmont, CA: Wadsworth Cengage Learning.

Kua, E. H., \& Lim, L. L. (2011). Living alone, loneliness, and psychological well-being of older persons in Singapore. Current Gerontology and Geriatrics Research, 2011, 1-9. doi: 10.1155/2011/673181

Killeen, C. (1998). Loneliness: An epidemic in modern society. Journal of Advanced Nursing, 28(4), 762-770. doi: 10.1046/2Fj.1365-2648.1998.00703.x

Miller, R. S., Perlman, D., \& Brehm S. S. (2007). Intimate relationship (4th ed.). New York, NY: McGraw-Hill.

Moustakas, C. E. (1961). Loneliness. Upper Saddle River, NJ: Pentrice-Hall, Inc.

Myers, D. G. (2010). Social psychology (10th ed.). New York, NY: McGrawHill.

Nanda, D. I. (2013). Hubungan loneliness dan psychological well-being pada dewasa muda lajang yang berkarir. (Skripsi, Universitas Bina Nusantara). Diunduh dari http://thesis.binus.ac.id/Doc/Lampiran/ 2012-1-00407-PS\%20Lampiran001.pdf

Pisca, N. E., \& Feldman, D. B. (2009). Purpose in life. In S. J. Lopez (Eds.), The encyclopedia of positive psychology (pp. 812-815). West Sussex, UK: Blackwell Publishing.

PT berkualitas belum merata. (2008, Juni 17). Kompas.com. Diunduh dari: http://nasional.kompas.com/read/2008/ 06/17/17241053/pt.berkualitas.belum. merata

Robitschek, C., \& Spering, C. (2009). Peronal Growth Initiative. In S. J. Lopez (Eds.), The encyclopedia of positive psychology (pp. 682-685). West Sussex, UK: Blackwell Publishing.

Roth, G., \& Deci, E. L. (2009). Autonomy. In S. J. Lopez (Eds.), The encyclopedia of positive psychology (pp. 78-82). 
West Sussex, UK: Blackwell Publishing.

Ryff, C. D. (1989). Happiness is everything, or is it? Explorations on the meaning of psychological well-being. Journal of Personality and Social Psychology, 57(6), 1069-1081.

Ryff, C. D., \& Keyes, C. L. M. (1995). The structure of psychological wellbeing revisited. Journal of Personality and Social Psychology, 69(4), 719-727.

Santrock, J. W. (2005). Psychology (7th ed.). New York, NY: Mc-Graw Hill.

Santrock, J. W. (2008). Essentials of lifespan development. New York, NY: Mc-Graw Hill.

Sønderby, L. C., \& Wagoner, B. (2013). Loneliness: An integrative approach. Journal of Integrated Social Sciences, 3(1), 1-29. Diunduh dari www.jiss.org.

Talamati, B. P. (2012). Hubungan antara trait kepribadian neuroticism dan psychological well-being pada mahasiswa tingkat akhir Universitas Indonesia. Skripsi. Diunduh dari http://lib.ui.ac.id/file?file=digital/20357 884-S-Blanca.pdf

Taylor, S. E., Peplau, L. A., \& Sears, D. O. (2006). Social psychology (12th ed.). New Jersey, NJ: Pearson Education Inc.

Walsh, W. B. (2009). Person-environment fit. In S. J. Lopez (Eds.), The encyclopedia of positive psychology (pp. 691-693). West Sussex, UK: Blackwell Publishing.

Wikanestri, W., \& Prabowo, A. (2015). Psychological well-being pada pelaku wirausaha. Seminar Psikologi dan Kemanusiaan, 431-439. Diunduh dari http://mpsi.umm.ac.id/files/file/431439\%20Winilis.pdf 